\title{
LA MONTAÑA MÁGICA Y LA COVID-19. LA LITERATURA SIEMPRE
}

\author{
THE MAGIC MOUNTAIN AND COVID-19. LITERATURE THROUGH \\ THE YEARS
}

\author{
Silvia Álvarez-Arana \\ silvia.alvarez@unach.mx \\ Gabriel Velázquez Toledo \\ gabriel.toledo@unach.mx
}


Para citar este artículo:

Álvarez-Arana, S., \& Velázquez Toledo, G. (2020). La Montaña mágica y la COVID-19. La literatura siempre. ESPACIO I+D, INNOVACIÓN MÁS DESARROLLO, 9(25). https://doi. org/10.31644/IMASD.25.2020.a12

\section{RESUMEN}

La intención del presente ensayo es mostrar la forma en que la novela alemana La Montaña mágica (1924) de Thomas Mann, capturó, desde diversas aristas, los efectos que el aislamiento y la enfermedad son capaces de producir en la mente humana. Dado que lo hizo de tal forma que, a cien años de distancia entre la tuberculosis y la COVID-19, la vigencia del argumento y el desarrollo en los personajes del cúmulo de acciones y emociones se repite como un modelo arquetípico en la actualidad. Para esto, se establece una suerte de paralelismo entre la imagen estética de los estragos en la psique del protagonista y las incipientes conclusiones que en materia de salud mental, en torno a esta crisis sanitaria, se han desarrollado hasta el momento.

\section{Palabras Clave:}

Covid-19, Confinamiento, Thomas Mann, Montaña mágica, Imagen. 


\section{- Abstract-}

The purpose of this essay is to show how the German novel The Magic Mountain (1924) by Thomas Mann captured, from different perspectives, the effects that isolation and diseases have on the human mind. The author wrote it in such a way that, even after the 100-year gap between tuberculosis and COVID-19, the argument's relevance and the characters' development through their actions and emotions are a reflection of the current archetype. Thus, we can notice a parallel between the aesthetic image of the havoc in the protagonist's psyche and the emerging conclusions about mental health during this crisis, that have been growing thus far.

\section{Keywords:}

Confinement, Covid-19,Thomas Mann, Magic Mountain, picture. 
¡Adiós Hans Castorp, hijo mimado de la vida! ¡Adiós, vas a vivir o a caer!

(Thomas Mann, 1924)

L

a pandemia ocasionada por el virus SARS-CoV-2 ha provocado una intensa reflexión sobre la salud mental de los seres humanos al sentirse confrontados con la mortalidad y con la restricción social, como ha sucedido durante estos meses de confinamiento.Aquí exponemos una reflexión desde lo literario, si bien la literatura no ha dado respuestas prácticas a las problemáticas sanitarias, sí ha tenido aproximaciones certeras y agudas sobre este tipo de fenómenos y la respuesta social ante ellos.

Jean Paul Sartre afirma que "es el objetivo final del arte: recuperar este mundo mostrándolo tal cual es, pero como si tuviera su fuente en la libertad humana" (2003:98). De la libertad de crear, mediante la escritura, y de leer, como un acto creativo, podemos encontrar varios ejemplos que van desde las tragedias griegas hasta Édipo Rey de Sófocles (496-406 A.E.C.), hasta novelas como La peste (1947) de Albert Camus (1913-1960), El amor en los tiempos del cólera (1985) de Gabriel García Márquez (I927-20|4), Ensayo sobre la ceguera (1995) de José Saramago (1922-2010) y muy recientemente, la profética novela The eyes of the darkness (198I) de Dean Koontz (1945-), por mencionar solo algunas. Por su puesto, es inevitable pensar en La montaña mágica, escrita en 1924 por el alemán Thomas Mann (I875-1955) Premio Nobel de literatura en 1929, considerada como la más importante de su autor, $y$ un referente de las letras alemanas del siglo $X X$.

Dentro del balance prematuro de las afectaciones por la pandemia, por muy profundas y graves que sean, no estamos, desde ninguna disciplina, ya sea científica o artística, en condiciones de hacer una evaluación conclusiva de éstas, toda vez que aún estamos en pleno desarrollo de la enfermedad. Ya varias universidades, sobre todo en el continente europeo y asiático, han bosquejado evaluaciones, diagnósticos y pronósticos, desde su triste posición de avanzada. Por la cercanía cultural con Europa, llegó en tiempo real la crónica anunciada de lo que luego sucedería en América exponencialmente. Justo es aquí donde la literatura encuentra su sitio en medio del caos mundial, a partir de su carácter icónico, el mismo que le permitió a Thomas Mann visualizar un escenario muy similar al que habitamos desde inicio del 2020, casi con un siglo de antelación.

La Montaña mágica contiene imágenes tan vigentes, que recuerdan a aquellas con las que cohabitamos este año: hastío, ansiedad, muerte, amor, amistad, enfermedad, miedo y soledad. Con una distancia de cien años, el protagonista de la novela, Hans Castorp, vive lo mismo que millones de personas de clase media, que se vieron obligadas a confinarse por meses. Esto se explica a partir del concepto de imagen poética de Viktor Shklovki 
(2002) en el que afirma que no son las imágenes las que varían, sino el procedimiento con que se analizan, toda vez que éstas han sido creadas con una intención estética. La imagen permanece (sujeto), la mirada es la novedosa (actualidad)'. La tuberculosis representada por Mann está en el mismo punto incipiente y voraz en el que nos encontramos por la COVID-19.

El oxímoron "nueva normalidad", con que se ha dotado a nuestro status quo, tiene grandes coincidencias con el cambio que representó para la humanidad la Primera Guerra Mundial, tiempo en que transcurre la historia del protagonista en la novela. Hans Castorp vive un confinamiento similar al que hemos padecido este 2020 (la diferencia es que él parte, de forma voluntaria, hacia un lugar en el que se ha de enfrentar a condiciones de incertidumbre similares a las que, de forma obligada, hemos padecido estos meses). Más allá de los parecidos evidentes, perturba cómo, frente a la ruptura de la "normalidad","rutina" o "costumbre", el hombre (considerando que tiene sus necesidades básicas cubiertas) oscila entre el ocio, la seducción y el miedo, pero, sobre todo, responde con la relativización de aquello que consideraba importante.

El protagonista asiste de visita a un sanatorio, apartado y solitario en los Alpes suizos, en el que dan tratamiento a enfermos con tuberculosis. Al llegar a la estación, se encuentra con su primo Joachim Ziemssen, quien le advierte: “¡Oh! El tiempo” (...) No puedes ni imaginar cómo abusan aquí del tiempo de los hombres. Tres meses son para ellos como un día. Ya lo verás. Ya te darás cuenta- Y añadió- Aquí las opiniones cambian” (Mann, 1998, p. 19). La idea de la relativización del tiempo en el confinamiento está presente durante toda la novela, incluso el lector termina por perder la noción del tiempo cronológico, pues pasa a segundo término. Castorp cree que está de paso, que ha llegado para tener una experiencia más, como cualquier otra, sin embargo, sucumbe finalmente a la visión del tiempo relativo, conforme su estadía en confinamiento se prolonga, conviviendo con el pesimismo de la enfermedad y la relatividad de la percepción de lo real:

Hans Castorp (...) no tenía la intención de tomar este viaje particularmente en serio, de mezclar en él su vida interior, sino más bien de realizarlo rápidamente, hacerlo porque era preciso, regresar a su casa tal como había partido y reanudar su vida exactamente en el punto en que la abandonó por un instante (1998: 15).

$1 \quad$ "La relación de la imagen con lo que ella explica puede ser definida de la siguiente manera: a) la imagen es un predicado constante para sujetos variables, un punto constante de referencia para percepciones cambiantes; b) la imagen es mucho más simple y mucho más clara que lo que ella explica." (Shklovski, 2002) 
En estos diálogos de Ziemssen, se observa una percepción del tiempo que difiere con la de Castorp (visión interior vs.Visión exterior), el primero no tiene ninguna prisa, en tanto que Hans piensa en volver a su rutina lo más pronto posible. Lo anterior nos recuerda a los últimos días de marzo en México, cuando usábamos la frase "cuando esto pase" para referirnos a un periodo corto que vendría después del confinamiento, el que pensamos que, quizá, se trataría a lo mucho de un mes; luego este tiempo se extendió hasta hoy mismo. El tiempo se relativizó, el primer mes de confinamiento fue largo, ahora, los meses recientes son muy breves, el año está por terminar y lo que antes era un anhelo, ahora no es más que un triste recuerdo, que se llena de incertidumbre y miedo, cuando el tan anhelado momento de libertad, de rompimiento de la cuarentena, llega de la mano de conductas disruptivas que han acarreado graves consecuencias para la salud pública, junto a medidas restrictivas severas respecto a las medidas sanitarias con que debemos aprender a convivir.

De nuevo, una imagen de Mann es pertinente para explicar nuestra realidad: "Tres semanas no son nada para nosotros, pero para ti, tres semanas son mucho tiempo. Comienza por aclimatarse, no es tan fácil, ya te darás cuenta. (...) Lo de regreso dentro de tres semanas es una idea de allá abajo"(2008:18). Para nosotros, esta deconstrucción temporal llegó hasta los espacios laborales, en los que las jornadas parecen no tener fin y en el que se ha perdido el respeto por los tiempos libres, vitales para los trabajadores. Se ha interpretado que, dentro del trabajo a distancia, home office o teletrabajo, el empleado debe estar disponible sin ninguna restricción, pues al no cumplir una jornada, debe resarcir esto con disposición, bajo la amenaza implícita de perder un empleo que, para las condiciones en las que se ha desenvuelto la pandemia en muchos hogares, parece ser un privilegio al que se nos permite acceder.

Thomas Mann divide su espacio narrativo en arriba y abajo. Arriba para el hospital, en donde se recluye al enfermo y abajo para los sanos. Dos mundos semióticamente opuestos. En este sentido, no se puede vivir como se vive abajo estando arriba. Es necesario aprender las reglas que la enfermedad impone, convivir con ellas, aceptar las que la pequeña sociedad "de arriba" del sanatorio, ha creado. Por ello, el protagonista desde el inicio se topa con la limpieza, los hábitos nuevos, adquiridos con la virtud fundamental de no aumentar la carga viral que puede atacarles, lo que les transforma en una condición obligatoria, extraña para los de "abajo”: “Fumigaciones? eso de fumigar es muy habitual (...)Sí (...) los microbios más resistentes no soportan. La limpieza es una condición primordial” (I998:25).

Asignado a una habitación en la que recién ha muerto una mujer de aquella enfermedad, el protagonista habrá de conocer esta anulación de la vida misma, o de lo que entiende por vivir, en un contexto social, al enfrentarse 
a una serie de rígidas normas con las que debe reconfigurar su forma de convivencia. Lentamente, Hans Castorp sufrirá cambios en su psique y su cuerpo al permanecer en ese hospital para tuberculosos, y es precisamente esta transformación del personaje, la que termina por ser tan similar a lo que nosotros mismos hemos observado transcurrir en muchos individuos, como respuesta orgánica a la actual pandemia. Por lo pronto, los primeros estudios coordinados por la Universidad del País Vasco arrojan que a causa de la COVID-I 9 sufriremos afectaciones en ámbitos psicológico y físico:

Durante el confinamiento, los dos factores que más afectan al bienestar físico y psicológico son la pérdida de hábitos y rutinas y el estrés psicosocial, de acuerdo con el primer estudio que analiza el impacto psicológico de la cuarentena por COVID-19 en China (Wang, Pan et al., 2020). La interrupción de hábitos durante el confinamiento y la instauración de otros poco saludables (p.ej. malos hábitos alimenticios, patrones de sueño irregulares, sedentarismo y mayor uso de las pantallas) pueden derivar en problemas físicos. (Balluerka, 2020:6)

La Montaña mágica alude a una montaña en Davos, Suiza, en que se encuentra el Sanatorio Internacional Berghof; sin embargo, también resulta la imagen del trayecto que Castorp atraviesa desde su llegada a dicho hospital, su ascensión al "nuevo" orden que priva ahí arriba y su futuro descenso, transformado en otro hombre, por un proceso casi mágico, que es producto del confinamiento. Esta analogía se presta a coincidencias con los días que vivimos, en los que saltamos de las famosas "curvas" epidémicas (esperando llegar a la cúspide que permita vislumbrar en el descenso una salida a la situación que vivimos), al confinamiento, que acarrea perturbadores estados mentales, en donde la desesperación, el hastío y la ansiedad han puesto en evidencia la fragilidad de la psique del individuo moderno, la que ha transitado por una modalidad que conocemos como "vida virtual”, la que es un producto del aislamiento, que se caracteriza por el uso de la tecnología de una forma nunca antes vista, mucho mayor a la que ya teníamos antes de 2020 , con la variante de la obligatoriedad.

No sabemos si nuestras transformaciones internas sean permanentes, pero es un hecho que se ha dado un replanteamiento axiológico de lo que creíamos antes y después de la pandemia. Para Mann la vida es el otro extremo de la muerte, su afirmación lógica, no obstante, es el único instinto que no se transforma ni se matiza a pesar de las contingencias “¿Qué era la vida? Nadie lo sabía. Nadie conocía el punto de la naturaleza de que nacía o en qué se encendía. Nada era espontáneo en el dominio de la vida a partir de ese punto, pero la vida misma surgía bruscamente" (I998: 293), tal y como nos ocurre en el presente. 
De nuevo puntualizamos que el ejemplo es pertinente para plantear la vigencia de la imagen literaria, pues queda claro que la pandemia ha sido diferente para todos, cada quién a vivido sus afectaciones en distinto nivel, las que se han visto reflejadas a nivel psicológico. En el caso del paralelismo que establecemos con Hans Castorp, hay que especificar que se trata de un joven sin problemas, que al llegar al sanatorio no tiene objeto ni propósito en la vida y que ha llegado hasta aquel lugar remoto porque se ha dejado arrastrar por la falta de un sentido. Y es precisamente en la construcción de este sentido que se refleja el papel fundamental de la enfermedad y el aislamiento en la voluntad de los enfermos, que cargan con la resignación a cuestas de un padecimiento que probablemente puede llevarlos a la tumba; pero la enfermedad también tiene poder sobre el hombre sano, aquel que construye su patología a través de una carencia ontológica.

Castorp, recibe el mote de "hijo mimado de la vida" al mostrarse como un ser banal, incapaz de apreciar las cosas que no están dentro de su noción de lo “bueno". Mann nos permite ubicarlo a través de la percepción que el Dr. Behrens, se ha forjado, en el que señala su debilidad:

Castorp, viejo tronco, usted me fastidia. Me hace la vida imposible, leo cada día en su frente su mal humor. Es usted un tipo agotado. Castorp, ha sido mimado por las sensaciones, y si no le propone cada día una novedad en primer orden se enfurruña durante todo el tiempo de las vacas flacas (Mann, 1998:864).

En el diálogo anterior tenemos la revelación de la naturaleza narcisista (tipos agotados, mimados por las sensaciones) que también vimos aflorar en muchos de nosotros durante esta pandemia. Paradójicamente, según el estudio citado anteriormente, las personas de clase alta que conservaron el empleo, entre más jóvenes eran manifestaron tener más soledad, ansiedad, depresión y en general carencias.

Según se muestra en la Tabla 4.8, el malestar psicológico fue del 4I\% tanto en hombres como en mujeres, tomando como referencia algún grado de cambio negativo (puntuaciones 4 y 5 de la escala). Sin embargo, un 12\% de mujeres informaron de mucho incremento de malestar psicológico respecto al 6,8\% de los hombres. Por edades se encuentra una relación inversa por la que, a mayor edad, menos empeoramiento del malestar (53\% entre los 18-34 años, $44 \%$ entre los 35 y 60 y $34 \%$ en los mayores de 60 años). No se apreció una clara tendencia que relacionara el nivel socioeconómico con el hecho de permanecer sin cambios, pero sí parece que los de nivel alto habían empeorado algo más (44\%) que los niveles medios (39\%) o bajos (40\%). No se encontraron grandes diferencias en malestar general en función del nivel de incidencia (baja, media o alta) de la zona de residencia, ni tampoco una tendencia clara" (Balluerka, 2020:82). 
Sin importar el continente, el estado de bienestar o el Índice de Desarrollo Humano, las voces egoístas de aquellos que actúan según sus intereses, no tardaron en manifestarse. Vemos imágenes de multitudes de individuos (como Castorp) que sin tener en cuenta la necesidad de un interés supremo, la vida, reflejaron esta forma infantil, mimada, preponderantemente solitaria, de quien es incapaz de sentir empatía por el prójimo. En nuestro personaje podemos encontrar que, al encontrarse fuera de su zona de confort, muestra una personalidad vacía, automatizada, que necesita de su peculiar sentido del goce para no caer en la depresión que se asoma detrás del sinsentido que se representa mediante su vacuidad. Es a esta misma a la que se han abandonado gustosamente quienes reclaman el respeto a su derecho de ser libres (de salir a la calle, de no tomar medidas sanitarias o de violentar aquellas que no son de su agrado), pues son los estándares y valores con que la "vida digital" se desarrolla. Estas expresiones se han matizado por el aparente miedo a perder la libertad, tanto en la vida real como en la novela.A esto, el mentor de Castorp, Settembrini, dirá una frase fulminante:"La libertad es la ley del amor de los hombres" (Mann, 1998:536)

A partir de las nociones que el personaje principal va recogiendo en sus observaciones cotidianas y en las conversaciones con los otros, los internos, que viven en carne propia la enfermedad y que han aprendido a priorizar sus circunstancias, es que su percepción de la temporalidad termina por verse afectada; así como sucede con la personalidad de cada uno, que ante la fragilidad de la vida encuentra su identidad en los hábitos y en las acciones que nos definen. Así nos revelará que las relaciones en el encierro son, para algunos, una alianza con la que enfrentar a la muerte de forma digna, mientras que para otros es el inicio del sentido, la recuperación de una fuerza que se sustenta en el apoyo mutuo, en el intento por recuperar la cordura, por reintegrarse al ente social, por permanecer y pertenecer a algo. En el caso del protagonista de la novela, pasará de un estado de frustración total e inadaptabilidad a otro de desazón total, antes de ver su transformación concluida:

Desde este momento le parecía al joven Castorp que algo flanqueaba en la vida; se le antojaba que iba a cada vez peor, y que una ansiedad creciente se había apoderado de él, como si un demonio se hubiese hecho cargo del poder, un demonio peligroso y burlón que desde hacía algún tiempo había desempeñado un papel bastante importante y que ahora acababa de proclamar, sin reservas, su autoridad, inspirando un terror misterioso y sugiriendo pensamientos de huida, un demonio que tenía por nombre <embrutecimiento> (Mann, 1998:867).

Esta cita, que refiere a un estado de embrutecimiento, es la imagen del generalizado cansancio tras estar más de medio año confinados, en el caso 
de los mexicanos cabe acotar que éste siempre ha tenido un carácter voluntario, de responsabilidad mutua y solvencia económica. Durante estos meses de confinamiento, las personas se manifiestan constantemente en redes sociales (principal canal de desfogue de la sociedad en esta pandemia) exhibiendo su cansancio, aburrimiento y hastío, a pesar de que reconocen que su vida, antes de la pandemia, no era diferente, no salían asiduamente ni frecuentaban a sus familiares y amigos. Es decir, la enfermedad ha sido también un asunto de percepción, lo que creemos ver como algo impuesto, no es más que la revelación de profundas carencias afectivas, emocionales e intelectuales, que han transformado el orden relativo de necesidades, de aquello que brinda un sentido a la vida. Hubo meses en los que la población exigía que el confinamiento en México fuera obligatorio y observado por la ley, mucho se insistió en la economía precaria de la mayoría, no obstante, estos sentimientos de aburrimiento y hastío, como ya vimos, no son preponderantes de las clases sociales más necesitadas. En el mismo estudio de Balluerka (2020:8), se habla de dos tipos de afectaciones a nivel psicológico durante y tras el confinamiento:

a) Aquellas que se pueden considerar afectaciones específicas por estar causadas por uno o varios estímulos relacionados con el contexto de la COVID-I9 (...) b) Afectaciones de tipo inespecífico, en las que no es posible identificar un estímulo desencadenante particular, más que el conjunto de cambios contextuales derivados de la pandemia y del confinamiento.

Es decir que, de acuerdo con lo anterior, solo en el primer caso podríamos hablar de consecuencias fatales como familiares enfermos, pérdidas económicas reales o situaciones tales como exceso de estrés familiar o violencia. Sin embargo, en el caso de las segundas serían las que provienen del contexto de lo que en México se ha llamado "nueva normalidad": la vida virtual, la soledad (o la convivencia forzada con los familiares junto con la falta de espacio para una realización individual), la intromisión de los otros a la intimidad del hogar a través de las cámaras y pantallas, entre otros; estos últimos no tienen relación con las necesidades básicas, ni con la proximidad con la enfermedad, ni con la muerte o no conscientemente. Las primeras pertenecen al orden de lo real, las segundas al orden de lo mental; ambas de igual importancia en la vida de cualquier individuo. Ejemplo de lo anterior es la condición que hemos visto crearse, el estado permanente de alerta, que raya ahora en la paranoia. Cualquier síntoma, ya sea real o imaginario, provoca una catarsis, que en el mejor de los casos se refleja en un nivel psicológico, a manera de estrés, pero que, en otros, ha llevado a crisis con repercusiones de tipo fisiológico. Convivir con los síntomas del virus que ahora nos mantiene en estado de alerta, eleva en nuestra conciencia el nivel 
de incertidumbre, que no podemos controlar, pues si las situaciones imaginarias provocan estrés, el miedo a contraer la enfermedad eleva la tensión y los niveles depresivos por la conciencia cercana de la muerte. Esto mismo es parte de la realidad a la que constantemente se enfrenta Castorp en el Sanatorio. La primera vez que ve a un enfermo con tuberculosis, recibe un golpe súbito de realidad:

Hizo una mueca y miró a su primo con los ojos dilatados. Se trataba con toda seguridad, de la tos de un hombre; pero de una tos que no se parecía a ninguna de las que HC había oído; sí una tos en comparación con la cual todas las demás habían sido testimonio de una magnífica vitalidad; una tos sin convicción, que no se producía por medio de sacudidas regulares, sino que sonaba como un chapoteo espantosamente débil (...) pero Hans Castorp no pudo dominar la impresión que le había causado aquella tos. Afirmó repetidas veces que era como si viese el interior de aquel caballero y cuando entraron en el restaurante, sus ojos, fatigados por el viaje, tenían un brillo un tanto febril. (Mann, 1998:27).

Entonces es claro que a la enfermedad propiamente dicha, al temor, al estrés por las condiciones impuestas, le sigue la inercia del surmenage, una fatiga mental crónica que se produce al repetir constantemente las desgracias, asociadas a la enfermedad, lo que nos mantiene prisioneros de nuestros propios fantasmas, o en términos de Mann: embrutecidos. Castorp también pasa por el hastío del confinamiento y se pregunta "Pero, ¿cuál es la causa de ese debilitamiento y esa oxidación que se debaten en una continuidad demasiado tiempo ininterrumpida? (1998; |47-|48). La respuesta nos la dará el propio Mann, al reflexionar que:

No es solo una fatiga del cuerpo y el espíritu gastados por las exigencias de la vida (pues para ésta el sencillo reposo sería el remedio más reconstituyente), sino también algo que atañe al alma: la conciencia de la duración, la vivencia del tiempo, que amenaza perderse en una monotonía persistente, la conciencia de que ella misma se halla emparentada y unida al sentimiento de la vida y que la una no puede ser debilitada sin que la otra sufra y se debilite a su vez. (Mann, 1998: I48)

Este estado de vacuidad responde entonces tanto a la falta de sentido como al exceso de autocontemplación y lo observar ver con o sin pandemia. Castorp, por su parte, lo padece dentro y fuera del sanatorio, sano y enfermo, hasta justo antes de su transformación final: “El hastío es, pues en realidad, una representación enfermiza de la brevedad del tiempo provocada por la monotonía” (Mann, 1998:I48). No es necesaria la pandemia para vivir en esta monotonía. 
Conforme la novela avanza, el joven protagonista tiene la fortuna de conocer a varios pacientes, que terminan por ser sus mentores. De su mano, se ve envuelto en una vorágine de información y de enseñanzas de las más diversas índoles, lo que lo sensibiliza a otros pensamientos y realidades que le hacen consciente de la importancia de virtudes como la creatividad, la razón, la seguridad en sí mismo, el valor y la fraternidad. Con todo ello descubre que es posible la trascendencia, aun en ese ambiente de muerte al que llega por unos días y en el que permanecerá por siete años, solo a partir de crear experiencias nuevas aún dentro del confinamiento:

Los grandes periodos de tiempo cuando su curso es de una monotonía ininterrumpida llegan a encogerse en una medida que espanta mortalmente al espíritu. Cuando los días son semejantes entre sí, no constituyen más que un solo día, y con una uniformidad perfecta la vida más larga sería vivida como muy breve y pasaría en un momento. (Mann, I998: |48)

En estos momentos estamos conscientes, en tanto el mundo nos lo demanda, que debemos permanecer en un estado de alerta no mecánico, como el que sugiere el autor alemán a fin de recuperar un poco del tiempo que ha pasado desapercibido: "Ese orden de experiencias se produce como una interrupción en el curso principal de la vida con el objetivo de recuperar, es decir, de cambiar y renovar el funcionamiento del organismo que corría peligro o comenzaba a debilitarse en el transcurso monótono de la existencia" (1998:147).

Y sin embargo, durante el confinamiento dejamos de estar conscientes, al punto de preguntarnos ¿en qué día vivo? Parece entonces que, como bien lo afirma el autor, la enfermedad ha dejado de ser propiamente una condición médica, cuando su impacto en la psique ha sido más profundo, trayendo consigo estados permanentes de ansiedad, de miedo o de una irracional negación que puede exponernos a otras tantas enfermedades, producto del debilitamiento mental. Castorp, en plena estadía en el sanatorio, al presentir que su presencia ahí no será breve y ante las privaciones a las que se somete, comprende que:

Sabemos perfectamente que la inserción de nuevas costumbres es el único medio de que disponemos para mantenernos vivos, para refrescar nuestra percepción del tiempo, para obtener, en definitiva, un rejuvenecimiento, una confirmación, una mayor lentitud de nuestra experiencia del tiempo, y por ello, la renovación de nuestro sentimiento de la vida en general (Mann, 1998:149).

La falta de lo que Mann llama "innovaciones" han provocado una elevación en el sentimiento de ansiedad, depresión, frustración e irritación, producto 
de la impotencia de no poder elegir la forma en que pasamos nuestro tiempo. No es el encierro en sí, es la obligación de encerrarse, convivir de forma forzada, mantener una relación con los otros que no nos permite una intimidad, porque no nos reconocemos en el ser que está ahí, sin poder salir. De ahí que sea casi indistinto el malestar que hemos experimentado en los últimos meses:

El $45 \%$ de hombres y el $52 \%$ de mujeres señalaron que habían experimentado mayores niveles de irritación y enfado. Se encontró una relación inversa en relación a la edad. Los más jóvenes informaron de un aumento de su irritación o enfado del $58 \%$, la franja intermedia del $47 \%$ y los mayores de 60 del 34\%. Las personas con un mayor nivel socioeconómico expresaron más incremento en sentimientos de irritación o enfado (50\%) que el nivel medio (45\% y el nivel bajo (45\%). No se apreciaron diferencias en función de la incidencia de la enfermedad en la zona en que se reside. Respecto a la situación laboral, el mayor incremento en irritación y enfado se dio en quienes habían perdido su trabajo temporalmente (56\%), frente a los que lo habían perdido definitivamente (48\%) o quienes lo conservaban (47\%). En estas últimas se apreciaba también un I $3 \%$ que señaló sentirse menos irritado que antes. Las personas que no formaban parte de un grupo de riesgo habían incrementado su irritación y enfado en mayor medida (50\%) que los que sí lo eran (4l\%); y los que vivían en pareja informaron de menor irritación que los que vivían solos o en cualquier tipo de composición familiar. (Balluerka, 2020:97).

Como ya se mencionó, la pandemia no perjudicó a todos de la misma forma. En el mejor de los casos las relaciones familiares se vieron favorecidas por las condiciones de reclusión que les trajeron oportunidades, disminuyeron su estrés, producto de sus condiciones de vida y trabajo. Para ellos, la pausa provocada por la pandemia es una oportunidad para emprender o replantear los procesos laborales.

La respuesta, entonces, la hemos dado nosotros mismos como hemos podido. Trabajando desde el hogar, leyendo, tomando e impartiendo cursos, aprendiendo a cocinar, reencontrando o asimilando las distancias irresolubles, mejorando los espacios, volviendo a habitarlos. Cada uno desde su espacio interior y con su propia reconfiguración axiológica. Lo importante, como hemos visto con el ejemplo de Thomas Mann, es más amplio y complejo que una "nueva normalidad", tendríamos que hablar en términos de costumbre, tal y como lo hizo Marcel Proust, quien consideró que ésta es una "celestina mañosa, sí, pero que trabaja muy despacio y que empieza por dejar padecer a nuestro ánimo durante semanas enteras, en una instalación precaria; pero que, con todo y con eso, nos llena de alegría al verla llegar, porque sin ella, y reducida a sus propias fuerzas, el alma nunca lograría hacer habitable morada alguna!”. Con el sentido de aceptación y no de ansiedad, 
de reconocimiento de nuestra realidad actual y no con la añoranza de un pasado que tampoco resultaba del todo favorable. Luego de seis meses, quizá estemos próximos a volvernos habitables para nosotros mismos y es esa la esperanza que nos mantiene vivos, la de participar en la visión de un mejor mañana.

Como se mencionó al principio, la literatura no está en condiciones, ni es su objeto, de dar una solución a esta crisis sanitaria. Lo cierto es que como lectores, podemos reconocernos en el tiempo pasado y ubicarnos en una posición privilegiada para observar la realidad. La literatura es humanidad, nos permite conocer con anticipación el futuro y lo más importante, vernos a nosotros mismos sin ningún velo ni prejuicio en la intimidad del lector y el libro. Para el filósofo francés Jean Paul Sartre, al leer:

...se prevé, se está a la espera. Se prevé el final de la frase, la frase siguiente, la siguiente página; se espera que se confirmen o se desmientan las previsiones; la lectura se compone de una multitud de hipótesis, de sueños y despertares, de esperanzas y decepciones; los lectores se hallan siempre más delante de la frase que leen, en un porvenir solamente probable que se derrumba en parte y se consolida en otra parte a medida que se avanza, en un porvenir que retrocede de página a página y forma el horizonte móvil del objeto literario" (2003:84)

Al estar frente a textos como el que aquí se comentó, estamos frente a un momento de liberación interna, mental, no de una ruptura del confinamiento. Castorp sale del sanatorio siendo un hombre que, ante la inminencia de la Primera Guerra Mundial, descubre su necesidad de tener un sentido, cualquiera que este sea: "Se puso en pie y miró alrededor, se vio salvado, liberado, no por sus propias fuerzas, como tuvo que reconocer para gran confusión suya, sino expulsado por las fuerzas elementales y exteriores para las que su liberación era completamente accesoria" (2008).

Nuestra expulsión de este maremágnum de la vida, en medio de una pandemia mundial, obedece a motivos netamente económicos, nuestra salvación, como sociedad, depende de la conciencia que hayamos logrado desarrollar a lo largo de los últimos meses, o de nuestro egoísmo simplista, el que antepone los pequeños placeres individuales a las grandes necesidades colectivas. La enfermedad requiere de sacrificios, algunos vinieron con la forma del tiempo y la locura, que están ahí, como un abismo, aguardando hacerse uno con el vacío, el sinsentido. Todavía no conocemos el fin de la pandemia, esperemos darle una respuesta afirmativa a la pregunta que Thomas Mann dejará sin respuesta: "De esta fiesta mundial de la muerte, de este temible ardor febril que incendia el cielo lluvioso del crepúsculo ¿se elevará algún día el amor?”. 


\section{REFERENCIAS}

Balluerka Lasa, Nekane (2020) Las consecuencias psicológicas de la COVID-19 y el confinamiento. Universidad del País Vasco/Euskal Herriko Unibertsitatea: https://www.ub.edu/web/ub/ca/menu_eines/noticies/ docs/Consecuencias_psicologicas_COVID-19.pdf

Coronavirus. Efectos psicológicos de una pandemia: el Estrés: http://ciencia. unam.mx/leer/995/coronavirus-efectos-psicologicos-de-una-pandemia-el-estres-

Mann, Thomas. (1998). La Montaña mágica (Séptima edición). Barcelona: Plaza \& Janes.

Proust, M. (2009) En busca del tiempo perdido. I. Por el camino de Swann. Madrid: Alianza Editorial.

Sartre, Jean Paul. (2003). ¿Qué es la literatura?. Buenos Aires: Editorial Losada.

Sholowski, V. (2002). El arte como artificio. En Teoría de la literatura de los formalistas rusos. México: Siglo XXI editores.

Universidad Nacional Autónoma de México (2020). Especiales Ciencia Unam: Coronavirus. Disponible en: http://ciencia.unam.mx/contenido/ video/290/coronavirus-asi-es-el-sindrome-de-la-cabana- 